\title{
Program for cross-cultural communicative competence improvement
}

\author{
Marina Krylova ${ }^{1, *}$, Aleksandra Proshkina ${ }^{1}$, and Natalia Bonushko ${ }^{1}$ \\ ${ }^{1}$ Saint-Petersburg State University of Economics, 21, Sadovaya street, 191023 St. Petersburg, Russian \\ Federation
}

\begin{abstract}
The development of the international market intensifies communication which increases the importance of their rational organization, as well as cross-cultural competence of participants in such interactions. The article provides a definition of cross-cultural competence. There are described the types of communicative audience of the company. It is defined a set of organizational and methodological support for programs to improve cross-cultural communication managers of the international company.
\end{abstract}

\section{Introduction}

The study of the topic of cross-cultural communicative competence against the global economic crisis may seem like a banal way to increase the costs. However, a more detailed study of this issue can change a similar view.

The need for cross-cultural competence arises in the process of cross-cultural communication. It can occur both inside the company and outside: in interaction in its external environment. When considering the cross-cultural competencies, the main attention is usually paid to the specifics of ethnic and national cross-cultural interactions. However, in a large enterprise, especially international, there are various subcultures (professional, generational, stratum) of communication between representatives. These communications require the formation and management [3, p. 23]. The lack of coordinated interactions between representatives of different subcultures leads to increased conflicts, to decreased motivation, etc. Therefore, the issue of cross-cultural competence is so significant.

It seems important to distinguish cross-cultural competence and cross-cultural communicative competence (hereinafter CCCC), since the issue of cross-cultural competence in the life of a company concerns not only communication issues, but also financial, economic, legal and others.

Also the issue of cross-cultural competence is important in case of cluster development. The fact of creating international innovation clusters is both a resource and a problem. The potential of the international innovation cluster is determined by the fact that it makes it possible to connect representatives of various areas to solve industry problems. The

* Corresponding author: $\underline{m}$ message@ 
problem is that representatives of various international companies that are members of such a cluster are carriers of their national and corporate cultures.

\section{Methodology}

Cross-cultural communicative interactions are revealed through the main communicative audiences of the organization's internal and external environment. Figure 1 shows the classification of cross-cultural audiences of the company.

The following communicative audiences were identified on the basis of an analysis of the external and internal environment of the organization:

- suppliers, competitors, customers;

- government structures (the interaction of an international company with this kind of audiences is usually diverse, among such institutions are government bodies, embassies, consulates, local authorities, customs, etc.);

- financial institutions (it is necessary to name various banks, monitoring bodies, investment companies, funds, brokerage houses, etc.).

- mass media: magazines, newspapers, TV centres, radio centres, Internet resources, etc.

The peculiarity of cross-cultural specificity is related to the difference in the principles of reporting the information in different cultures, the role of the media in society, the relationship between the media and the state and society, the degree of their influence on the business;

- public associations (trade unions, environmental groups, consumer societies, etc.). Cross-cultural differences are manifested through the methods and principles of group organization, the role of such associations in the life of the state, society and business;

- the population of the territories of the company. The attitude of the population to the activities of the company may be a factor in the creation of specific cross-cultural, image and reputation risks, which may negatively affect the activities of the company;

- target audience of the company. A company may have a stable market position, but at the same time it may lose it as a result of an illiterate cross-cultural communication policy, and market positioning without taking into account national specifics;

- founders, top management, staff of the company.

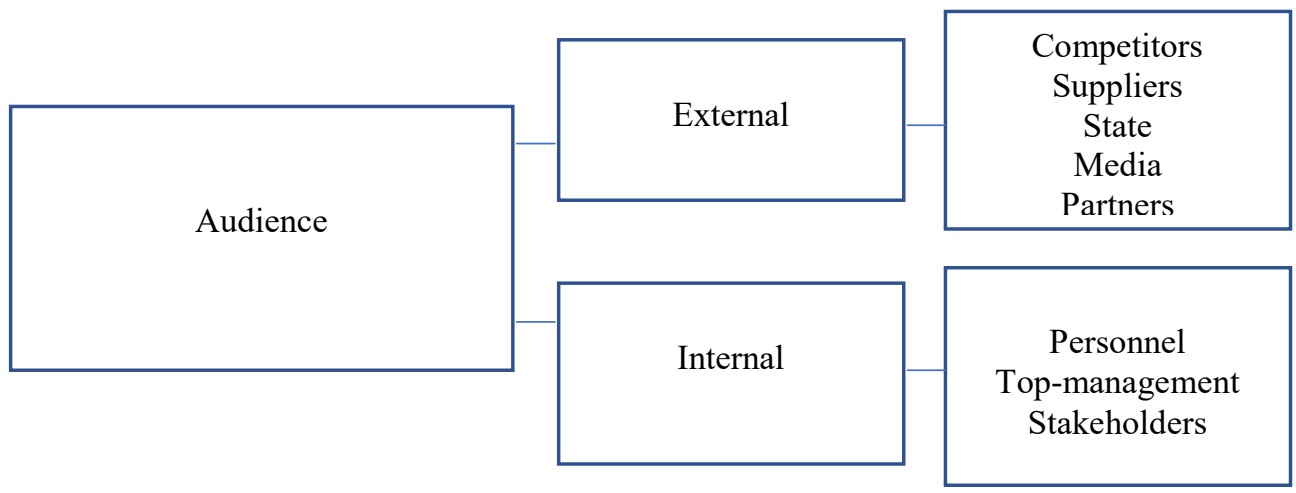

Fig. 1. The types of audience for CCCC.

\section{Research and results}

The issue of CCCC formation is directly related to the company's corporate culture and it is one of the most important issue in the life of an international company. A weak level of 
CCCC formation leads to inefficient use of the budget and demotivation of employees. Let's take a step-by-step look at the CCCC formation algorithm.

1. Creation of the concept of forming the CCCC. This stage involves the determination of the type of training that is necessary to solve the problems of this organization, and the level of training. Also the stage includes the clarification of relevant time and budgetary capabilities of the organization in the context of the CCCC.

2. Implementation of cross-cultural education. The following teaching methods can be used [4]:

- textual content in the form of textual instructions on cross-cultural behavior in the organization, dictionaries with Russian-language transliteration, textual materials related to the cultural characteristics that are presented in the organization. This method can be used in hiring as part of familiarization with the corporate culture, can be used jointly, for example, for the arrival of business partners;

- info-products: audio lessons on cross-cultural specifics, recordings training programs on $\mathrm{CD}$, digital products, auto-trainings, audio books of authors-carriers of the company's cultures;

- cross-cultural consulting (most often used by top managers in preparation for negotiations);

- online trainings as a part of corporate distance learning system, which can be extremely useful for foreign offices of the company;

- "live" trainings, conducted by the HR department of the company or by resource person.

Augmented reality has not yet included in corporate trainings, but it seems that such resource will be able to solve many problems in corporate training in the near future.

A detailed diagram of the algorithm of implementation of various forms of crosscultural learning is presented in Fig. 2.

A wide range of teaching methods is used in cross-cultural education, [4, p. 17]: business games, role-playing games, simulations, lectures and presentations, brainstorming, situational training, case solving, Aquarium techniques (2-3 people are working, others are observing), discussions, practical works, individual and independent training, and many others.

3. Analysis of options for developing a cross-cultural training program in order to determine the presence in the company such kind of specialists, who have experience in developing cross-cultural training programs, can conduct independent training, or invite specialists involved in cross-cultural competence. It is impossible to make clear choice between external and internal training, since the pros and cons, presented in the general case, may be absent in a particular implementation.

4. Formation of the cross-cultural education structure requires the determination of the category of the staff. Age, work experience, gender, ethnic composition, foreign experience, position in the company, knowledge of a foreign languages, level of education, duration of classes should be taking into account. Then, the persona of the coach should be specified to determine the financial and temporary conditions of training.

5. The choice of the content of training depends on its direction. This may be general cross-cultural training - cross-cultural marketing and management, foreign languages, etc., or special training directly related to the company's business.

To develop educational content, it is necessary: 1) to determine the cause of the crosscultural problem, 2) to determine the current level of knowledge of employees, 3) to determine the methods and conditions for attracting and selecting employees, as well as the time and the place of training, 4) to establish criteria and ways to measure of learning outcomes. 


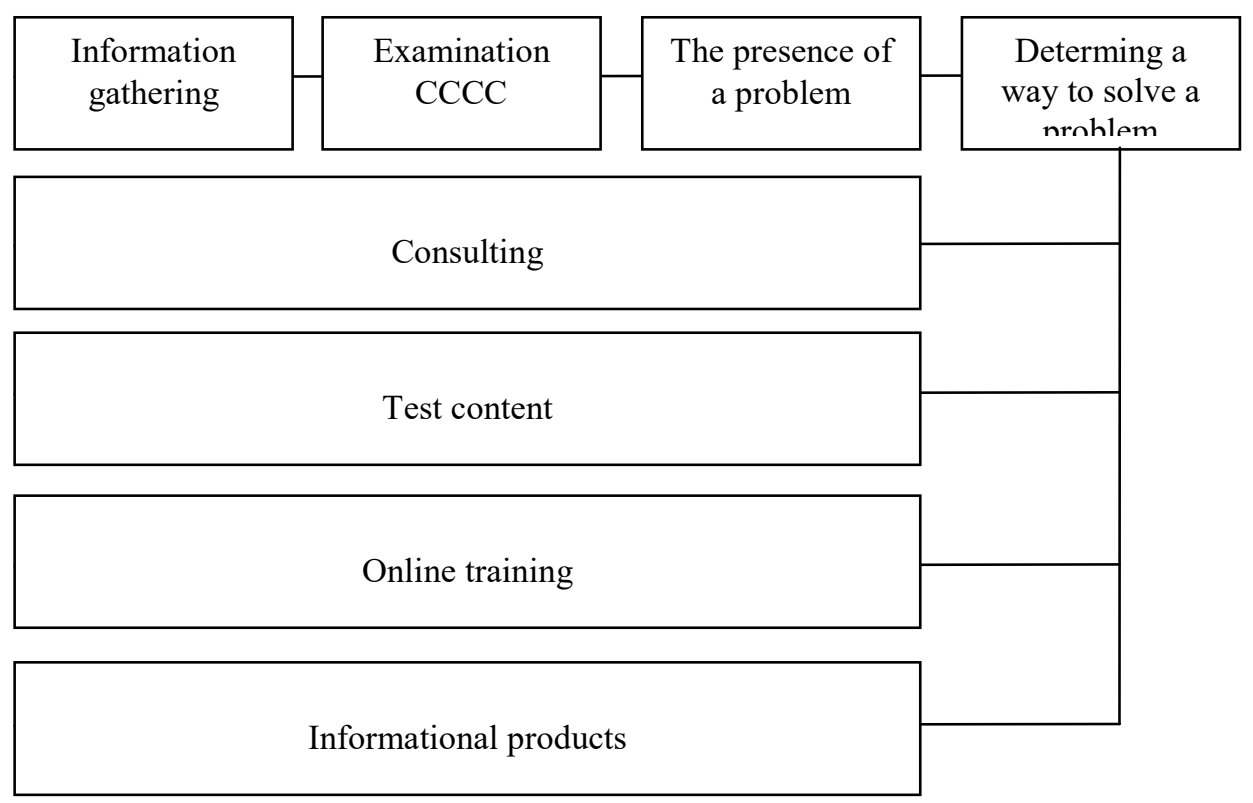

Fig 2. Algorithm for implementing various forms of cross-cultural learning

6. Definition of a specific set of knowledge, abilities and skills that employees need. To solve this issue, it will be productive to attract some specialists from the HR department, representatives from company management who maintain the communication with foreign partners. Experts on cross-cultural communications and company employees can be attracted as well. As a result of such interaction a formalized report is compiled. It should contain detailed requirements for the knowledge and skills of a person, who occupies a certain position, indicating specific requirements for this employee. The number of crosscultural competencies required for representatives of different levels of the organizational hierarchy will be different: from 3-4 for middle managers, up to 5-8 for top managers.

After determining the current level of knowledge, skills and weaknesses of the staff, a program is created that involves the elimination of all weaknesses. The training program should meet the following conditions: training topics should comply with the duties of employees, the training material should be understandable to students, the material should be conveniently structured using multi-media resources, and the training should be interactive.

7. The creation of evaluation system for results is necessary to ensure the high quality of the learning outcome. Such results can be achieved using 1) testing before and after training, 2) creation of evaluation system for test results, 3) creating a set of assessment tools such as tests, cases, cross-cultural assimilators, etc.

Among the main parameters that determine the system of assessment criteria for crosscultural learning, the level of the position in the company`s hierarchy and the complexity of the performed work [1]. The set of cross-cultural competencies for each position depends on corporate, managerial and professional requirements.

Assessment of training is an integral part of staff training. The inclusion of the CCCC in the appraisal assessment of the stuff's work will be an additional incentive for its improvement by employees, subject to its clear criteria. It is important to note that learning assessment is related to the difference in the roles of evaluators. The difference in 
assessment can be significant from the position of company management, HR specialists, trainers, psychologists. It will differ from the assessment of company employees.

8. Cost analysis: costs and benefits. One of the most important factors when choosing a training is its price, which consists of the following components [5, p. 34]: payment for the work of a trainer, agency, HR department, expenditures for consumables - felt-tip pens, flip chart, training materials and equipment, office supplies, transportation costs, food and accommodation in case of outreach classes, cost of maintaining the auditoriums, conference rooms of the company or rented areas, general overhead and unforeseen expenses.

In addition to the costly part, the significant benefits of the learning process can be distinguished:

- cost reduction, expressed in an increase in services provided, an increase in the number of customers served, as well as the complete exclusion of certain costs;

- reduction of time costs arising in cross-cultural interaction, expressed in an increase in the speed of services, a decrease in the time of meetings, preparation and conduct of negotiations;

- Improving the quality of corporate culture associated with a decrease in the level of conflict, a decrease in the number of complaints, and an improvement of mutual understanding.

- the growth of staff loyalty associated with the improvement of the psychological climate in the company, a decrease in psychological tension of the staff due to the more predictable communicative behavior of employees, an increase in the job satisfaction, an increase of self-esteem and self-confidence of company employees;

- an increase in the personal effectiveness of the staff by growth in the overall communicative and cross-cultural competence of the staff.

9. The creation and implementation of the program of CCCC's formation is the final step of the implementation of the learning process.

Active transformations in political, economic, social and cultural life require a significant restructuring of the management of the company's communications system. Such a transformation is especially necessary for international companies. The lack of attention to cross-cultural communications and neglect of the need to build cross-cultural communicative competence among all employees of the company, including the founders, leads to the failure of contracts, higher costs, increased conflict both inside and outside the organization, which is represented by cross-cultural communication audiences. So, the issue of forming a cross-cultural communicative competence is so important for an international company competency.

\section{References}

1. M. Nguyen-Phuong-Mai, Cross-Cultural Marketing (2019). DOI: 10.4324/9780203729915-14.

2. G. Fahhrutdinova, S. Fedorova, E. Vorontsova. A Cross-Cultural Situation. The European Proceedings of Social and Behavioural Science, 630-639 (2019). DOI: 10.15405/epsbs.2020.01.69

3. R. S. Cheney, Business Communication Quarterly 64(4) (2011). DOI: 10.2991/ismge-19.2019.63

4. G. Maletzke. Interkulturelle Kommunikation: Zur Interaktion zwischen Menschen verschiedener Kulturen. - Opladen: Westdt. Verlag (1996). DOI: 10.1007/978-3322-80350-4

5. J. Phillips. Return on investment in training and performance improvement programs. (London, New York: Routledge, 2011). DOI: 10.4324/9780080516257 